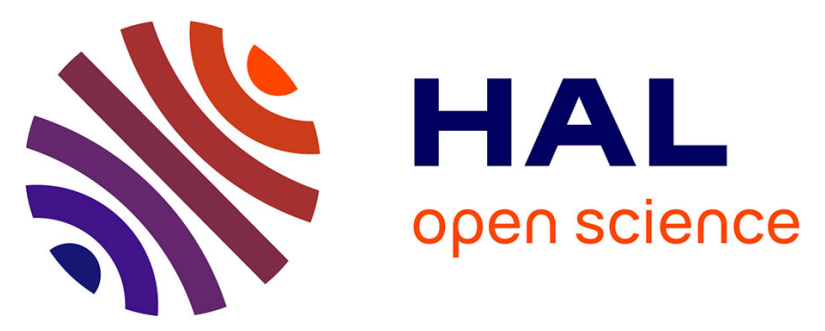

\title{
Ionic Polarization Occurrence in BaSrTiO3 Thin Film by THz-Time Domain Spectroscopy
}

Grégory Houzet, Karine Blary, Sylvie Lepilliet, Didier Lippens, Ludovic Burgnies, Gabriel Vélu, Jean-Claude Carru, Edwin Nguema Agnandji, Patrick Mounaix

\section{To cite this version:}

Grégory Houzet, Karine Blary, Sylvie Lepilliet, Didier Lippens, Ludovic Burgnies, et al.. Ionic Polarization Occurrence in BaSrTiO3 Thin Film by THz-Time Domain Spectroscopy. Ferroelectrics, 2012, 430 (1), pp.36-41. 10.1080/00150193.2012.677682 . hal-00718742

\section{HAL Id: hal-00718742 \\ https://hal.science/hal-00718742}

Submitted on 30 Aug 2018

HAL is a multi-disciplinary open access archive for the deposit and dissemination of scientific research documents, whether they are published or not. The documents may come from teaching and research institutions in France or abroad, or from public or private research centers.
L'archive ouverte pluridisciplinaire HAL, est destinée au dépôt et à la diffusion de documents scientifiques de niveau recherche, publiés ou non, émanant des établissements d'enseignement et de recherche français ou étrangers, des laboratoires publics ou privés.

\section{(1)(1) $\$(0)$}

Distributed under a Creative Commons Attribution - NonCommercial - ShareAlikel 4.0 


\title{
Ionic Polarization Occurrence in $\mathrm{BaSrTiO}_{3}$ Thin Film by THz-Time Domain Spectroscopy
}

\author{
G. HOUZET, ${ }^{1}$ K. BLARY, ${ }^{1}$ S. LEPILLIET, ${ }^{1}$ D. LIPPENS, ${ }^{1}$ \\ L. BURGNIES, ${ }^{1,2}$ G. VÉLU, ${ }^{3}$ J. C. CARRU ${ }^{3}$ E. NGUÉMA, ${ }^{4}$ \\ AND P. MOUNAIX ${ }^{4, *}$ \\ ${ }^{1}$ IEMN, UMR-CNRS 8520, Université de Lille 1, BP69, 59652, \\ Villeneuve d'Ascq cedex, France \\ ${ }^{2}$ Université du Littoral Côte d'Opale, Calais, France \\ ${ }^{3}$ UDSMM, EA-4476, Université du Littoral Côte d'Opale, Calais, France \\ ${ }^{4}$ LOMA, UMR-CNRS 5798 Université de Bordeaux 1, 351 Cours de la \\ Libération, 33405 Talence cedex, France
}

\begin{abstract}
$\mathrm{BaSrTiO}_{3}$ thin films in a paraelectric phase were characterized on the one hand from $1 \mathrm{GHz}$ to $200 \mathrm{GHz}$ by microwave measurements on interdigitated capacitance and coplanar waveguides and on the other hand up to $3 \mathrm{THz}$ by Time Domain Spectroscopy. An overlap of the polar nanoregion relaxation mechanism with a characteristic frequency around $800 \mathrm{GHz}$ and of the ionic polarization with a relaxation frequency around $3 \mathrm{THz}$ is directly evidenced experimentally.
\end{abstract}

Keywords Thin films; $\mathrm{BaSrTiO}_{3}$; complex permittivity; terahertz; microwave

\begin{abstract}
More and more microwave components use ferroelectric materials as a way to tune some characteristic behavior such as dielectric response [1-6]. With this aim for the physical point of view, the main challenge is to obtain a large voltage-control of the permittivity associated with dielectric losses as lower as possible. At room temperature, a few $\mathrm{BaTiO}_{3}$ (BT) based alloyed materials reach this trade off by giving a ferroelectric material in paraelectric phase, as the $\mathrm{Ba}_{\mathrm{x}} \mathrm{Sr}_{1-\mathrm{x}} \mathrm{TiO}_{3}$ (BST) material with a Barium concentration $\mathrm{x} \sim 0.5-0.6$. Origins of the material losses at microwave frequencies and millimeter wavelengths stem from various physical or structural mechanisms [7-10] which can coexist together. So, dielectric spectroscopy is an efficient solution to analyze relaxation phenomena in physical or structural point of view. To date, microwave measurements up to a few tenths of $\mathrm{GHz}$ can be found in literature $[4,5]$. At these frequencies, it is shown the preliminary decrease of the permittivity can be due to the interaction of ac-field with polar nanoregions (PNRs) [11]. On the other hand, at THz frequencies, IR-reflectivity measurements pointed out a dielectric dispersion effect by ionic polarization from phonon modes [11, 12]. Finally, some authors have predicted an overlapping of the two mechanisms at a few $100 \mathrm{GHz}$. In this work, we report on measurement results of dielectric dispersion in an extended frequencies band, ranging from $\mathrm{GHz}$ to $\mathrm{THz}$. Two de-embedding techniques have been used to retrieve
\end{abstract}


the complex permittivity value of BST thin films through InterDigitated Capacitors below submillimeter wavelengths. At higher frequencies from 0.2 to $3 \mathrm{THz}$, we used Time Domain Spectroscopy (TDS) measurements to retrieve the complex value of the permittivity.

\section{Material and Technology}

A $500 \mathrm{~nm}$-thick $\mathrm{Ba}_{0.5} \mathrm{Sr}_{0.5} \mathrm{TiO}_{3}$ film has been deposited by a sol-gel technique on a $1 \times 1 \times$ $0.05 \mathrm{~cm}^{3}$ sapphire substrate. Sol-gel method starts with Barium acetate, Strontium acetate, and Titanium (IV) isopropoxide to realize precursor solutions. Barium and Strontium precursors were solved into acetic acid at $100^{\circ} \mathrm{C}$ during 1 hour, before to add the Titanium precursor diluted in hot Isopropanol at $80^{\circ} \mathrm{C}$ during 2 hours. Then, the precursor solution was cooled down to room temperature. The thin film was deposited onto the substrate by a repeated spin coating process, and crystallized via a post-deposition annealing at $750^{\circ} \mathrm{C}$ for 1 hour in ambient air. Further details about the film deposition can be found elsewhere [13]. Film crystal quality and phase formation was studied by X-ray diffraction which has indicated that the film was in a pure perovskite structure and has shown a non-textured polycrystalline structures. Moreover, the film was dense without cracks, and with a grain size average of $50 \mathrm{~nm}$, as observed by a scanning electron microscopy (SEM).

Below millimeter wavelengths, complex permittivity measurements were performed with InterDigitated Capacitors (IDC) and CoPlanar Waveguide (CPW). IDC structures, with finger-shaped electrodes on a micron scale, were patterned by electron beam lithography in a polymethyl methacrylate electronic (PMMA) resist followed by Ti/Au deposition onto the BST film, by means of a lift-off technique. A photograph of an IDC is shown in Fig. 1(a).

\section{Microwave Measurements}

From $100 \mathrm{MHz}$ to $110 \mathrm{GHz}$, we used a Vector Network Analyzer (Agilent 8510C XF) with microprobes (Cascade technology). From $140 \mathrm{GHz}$ to $220 \mathrm{GHz}$, we used WR05 Oleson heads driven by a VNA (Rohde \& Schwarz ZVA24). From scattering parameters measurements, two de-embedding techniques have been developed to retrieve the complex permittivity value of BST thin films through IDC below submillimeter wavelengths.

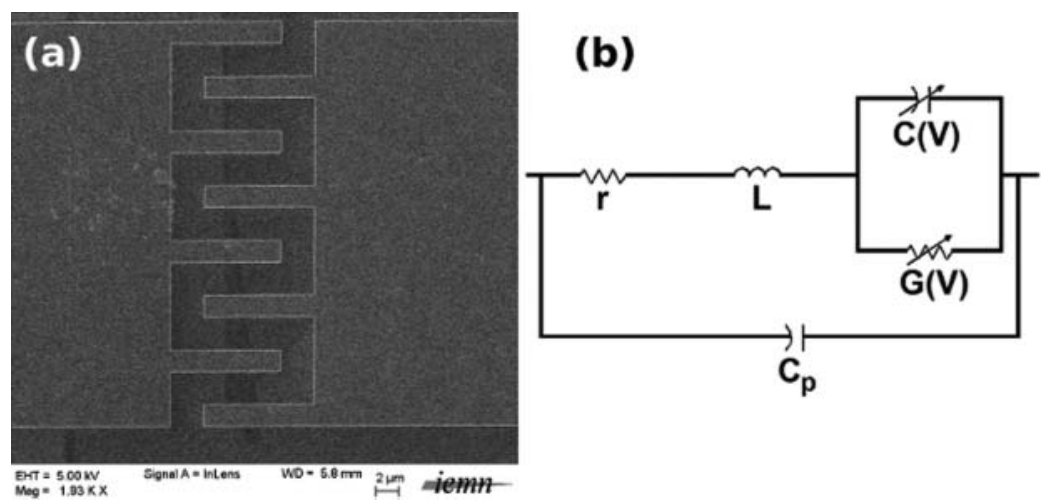

Figure 1. Photograph of an InterDigitated Capacitance (IDC) on a micron scale (a). RLC equivalent circuit of the IDC (b). 


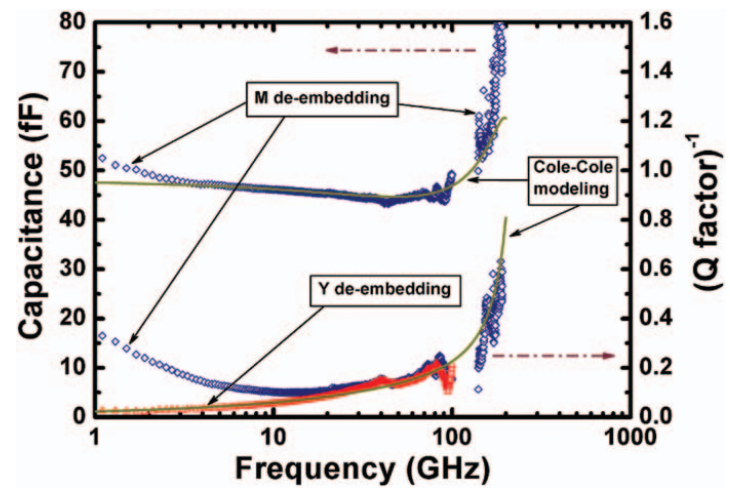

Figure 2. Frequency dependences of the apparent capacitance and of the inverse of the quality factor of the IDC (Figure available in color online).

Figure 2 shows the frequency dependences of the apparent capacitance, which reflects the real part of the permittivity, and of the quality factor retrieved by means of the two analysis methods named $\mathrm{M}$ - and Y-deembedding techniques respectively. The first one named M-deembedding technique permits us to obtain the frequency dependence of the capacitance and the inverse of the quality factor Q of the IDC above $10 \mathrm{GHz}$ and up to $220 \mathrm{GHz}$. The second one named Y-deembedding technique is more valid in the lower frequency part of the band investigated by VNA analysis typically at centimeter wavelengths. More explanations of the deembedding techniques can be found elsewhere [14]. From Fig. 2, it can be concluded that the M-deembedding technique gives the capacitance behavior of the IDC, and the loss tangent need both M- and Y- techniques. To obtain the dielectric dispersion in BST thin film, we use the equivalent RLC circuit of the IDC shown in Fig. 1(b) with a Cole-Cole function (Equation 1) for describing the dielectric dispersion in the BST film by PNRs (dipole polarization) [14, 15].

$$
\varepsilon^{*}(\omega)=\varepsilon^{\prime}-j \varepsilon^{\prime \prime}=\varepsilon_{\infty}^{\prime}+\frac{\varepsilon_{s}^{*}-\varepsilon_{\infty}^{\prime}}{1+(i \omega \tau)^{\beta}}
$$

The inductive (L) and resistive (r) parts of parasitic elements were determined with the help of mapping current densities calculated by full wave simulation (HFSS - Ansoft), while parasitic capacitance $(\mathrm{Cp})$ was determined by measurement. The BST thin film was modeled by a voltage-controlled capacitance $(\mathrm{C})$ and conductance $(\mathrm{G})$. These two voltagecontrolled parameters also depend on the frequency by using the dielectric dispersion given in Equation 1. Parameters of the Cole-Cole function are determined by fitting the complex dielectric dispersion from CPW measurements used for IDC techniques. Simple CPW transmission lines of different lengths permit one to retrieve the propagation constant, and a relaxation time $\tau=0.21 \mathrm{ps}$, and a power coefficient $\beta=0.6$ was estimated. The relaxation time value, lower than the typical value of BST ceramics at room temperature, can be seen as a signature of the hardening of soft-phonon modes in BST thin films. The coefficient $\beta$ corresponds to the distribution of the ac-field interactions with the soft phonon modes.

Above $50 \mathrm{GHz}$, the increasing apparent capacitance and (Q-factor) $)^{-1}$ appearing in Fig. 2 is attributed to the inductive behavior of IDC, while the dielectric dispersion in the BST thin film stills smoother as shown in Fig. 4. 


\section{TDS Measurements}

We use a standard THz-TDS transmission setup based on a mode-locked Ti-Sapphire laser providing $80 \mathrm{fs}$ pulses with a $76 \mathrm{MHz}$ repetition rate. The pump beam is focused onto a bare InAs layer for surface field emission of the THz pulse which is further detected with a photoswitch triggered by the probe. After emission, the $\mathrm{THz}$ beam is first collimated and then focused by means of two parabolic mirrors at the sample location. Upon its interaction with the sample, the time-resolved field variation is measured using the current generated in the LT-GaAs semiconductor receiver. This set up provides a frequency response up to $3.5 \mathrm{THz}$. In fact, a major advantage of this technique is that there is no need of a Kramers-Kronig analysis, since this experiment gives a direct access to the electric field amplitude.

The THz-TDS experiment, for the measurements of thin films, consists of three consecutive measurements for each sample: (i) Measurement of a waveform with an empty sample holder, (ii) Measurement of a Sapphire wafer substrate waveform, (iii) Measurement of a signal waveform with the thin film on a substrate. Measurements (i) and (ii) serve for the accurate determination of the dielectric properties of the substrate while measurements (i) (ii) and (iii) are used for the characterization of the thin film. The characteristics of the TDS set up, which was used in the present work, are illustrated in Fig. 3(a) by plotting the typical time dependence of the recorded signals at various time delays for the three aforementioned operation conditions. Figure 3(b) shows the amplitude Fourier transform of the reference $\mathrm{THz}$ pulse starting from $0.4 \mathrm{THz}$. At lower frequencies in practice below $0.2 \mathrm{THz}$, the radiated field amplitude is rapidly decreasing along with a dramatic decrease of the phase shift across the BST thin film. Under this condition, the determination of the refractive index via a time domain analysis is no longer accurate. On the other hand, it can be noted a signal above the noise floor can be detected roughly up to $3 \mathrm{THz}$.

To extract the dielectric function of the thin film in the terahertz range, we used the method described in ref 16. Briefly, the spectroscopic method consists in the calculation of the transfer function of the sample in the Fourier space and then the determination of the complex transmission function $T(\omega)$ of the sample. The multiple echoes due to internal reflections in the thin film are taken into account in the analytical expression of $T(\omega)$. The resulting non linear system is then numerically solved: it consists in two real equations for two real parameters $n$ and $\kappa$ ( the complex refractive index is $N=n+i \kappa$ ). As a result, we obtain the complex dielectric function of the sample in the entire spectral range
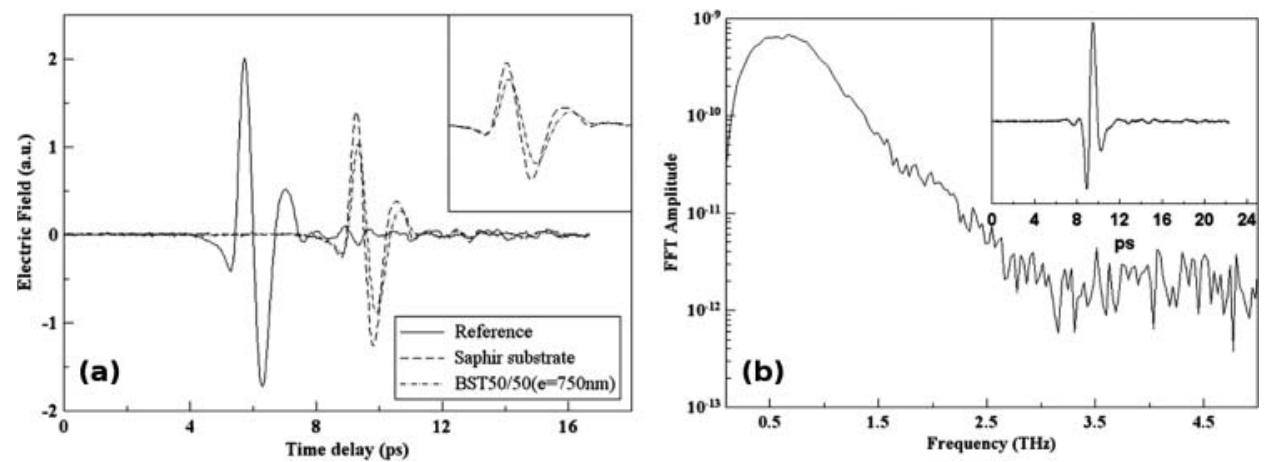

Figure 3. Reference, sapphire, and BST onto sapphire transmitted electric field in time domain (a). FFT amplitude of the THz reference pulse (b). 


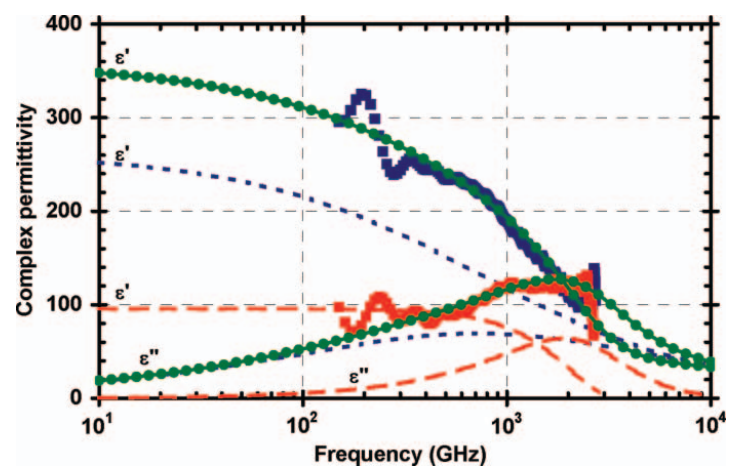

Figure 4. Complex dielectric dispersion of the BST thin film measured (square) and retrieved (circle) with dipole polarization part (dotted lines) and ionic polarization part (dashed lines) (Figure available in color online).

transmitted by the $\mathrm{THz}$ pulse without any ambiguity. The limiting factors are the planarity of the sample and the precision of the determination of its thickness [17]. Then, we get the complex permittivity $\varepsilon(\omega)=\varepsilon^{\prime}(\omega)+j \varepsilon^{\prime \prime}(\omega)=N^{2}(\omega)$ where $\varepsilon^{\prime}(\omega)$ is the real part and $\varepsilon^{\prime \prime}(\omega)$ is the imaginary part of the complex permittivity.

In Fig. 4, we compare the TDS experimental data (square symbols) with the frequency dependence of the complex permittivity $\varepsilon^{*}=\varepsilon^{\prime}$-j $\varepsilon^{\prime \prime}$ modeled by (i) a Debye-type relaxation mechanism according to equation 1 with a characteristic frequency around $800 \mathrm{GHz}$ (dotted blue line) and (ii) an ionic polarization mechanism by using equation 2 of reference [11] (dashed red line) with a characteristic frequency around $3 \mathrm{THz}$. For the latter, it had to be emphasized that a unique phonon mode was assumed. From Fig. 4, it can be noticed a good fit between the experimental results and the data achieved by the superimposition of the two aforementioned mechanisms. Around $800 \mathrm{GHz}$, the real part of permittivity decreases steeper while the imaginary part continue to increase instead of decreasing as it would be the case in a pure Debye relaxation mechanism. It is believed that this is the signature of an ionic polarization occurrence, as it was observed for BST ceramics [12, 18].

\section{Conclusion}

In conclusion, the dielectric dispersion of a BST thin film has been measured in a broad frequency range from $200 \mathrm{MHz}$ up to $3 \mathrm{THz}$ by various de-embedding techniques. Loss mechanisms have been analyzed in terms of ac-field interactions with local PNR (dipole polarization) in the lower frequency part, while ionic polarization effects appear at $\mathrm{THz}$ frequency. Overlapping between dipole polarization and ionic polarization has been experimentally observed at near $\mathrm{THz}$ frequency range for the BST thin film considered in the present work, as previously observed by Tsurumi et al [11] for a BST ceramic. The knowledge of the overlapping frequency can reflect the physical and structural properties of the film.

\section{References}

1. A. Marteau, G. Vélu, G. Houzet, L. Burgnies, E. Lheurette, J.-C. Carru, and D. Lippens, Appl. Phys. Lett. 94, 023507 (2009). 
2. F. Ponchel, J. Midy, J.-F. Legier, C. Soyer, D. Rémiens, T. Lasri, and G. Guéguan, J. Appl. Phys. 107, 054112 (2010).

3. J. H. Leach, H. Liu, V. Avrutin, B. Xiao, Ü. Özgür, H. Morkoç, J. Das, Y. Y. Song, and C. E. Patton, J. Appl. Phys. 107, 084511 (2010).

4. M. Ouaddari, S. Delprat, F. Vidal, M. Chaker, and K. Wu, IEEE Trans. Microwave Theory Tech. 53, 1390 (2005).

5. X. Y. Zhang, Q. Song, F. Xu, S. Sheng, P. Wang, and C. K. Ong, J. Phys. D: Appl. Phys. 42 , 065411 (2009).

6. S. Gevorgian, Ferroelectrics in microwave devices, circuits and systems, London: Springer, 2009.

7. K. F. Astafiev, A. K. Tagantsev, and N. Setter, J. Appl. Phys. 97, 014106 (2005).

8. G. Arlt, U. Bottger, and S. Witte, Appl. Phys. Lett. 63, 602 (1993).

9. M. P. McNeal, S.-J. Jang, and R. E. Newnham, J. Appl. Phys. 83, 3288 (1998).

10. M. J. Dalberth, R. E. Stauber, J. C. Price, T. Rogers, and D. Galt, Appl. Phys. Lett. 72, 507 (1998).

11. T. Tsurumi, J. Li, T. Hoshina, H. Kakemoto, M. Nakada, and J. Akedo, Appl. Phys. Lett. 91, 182905 (2007).

12. T. Teranishi, T. Hoshina, H. Takeda, and T. Tsurumi, J. Appl. Phys. 105, 054111 (2009).

13. G. Vélu, J.-C. Carru, E. Cattan, D. Remiens, X. Melique, and D. Lippens, Ferroelectrics 288, 59 (2003).

14. G. Houzet, K. Blary, S. Lepilliet, D. Lippens, L. Burgnies, G. Vélu, J.-C. Carru, E. Nguéma, and P. Mounaix, J. Appl. Phys. 109, 014116 (2011).

15. J. C. Booth, I. Takeuchi, and K.-S. Chang, Appl. Phys. Lett. 87, 082908 (2005).

16. J. Petzelt, P. Kužel, I. Rychetský, A. Pashkin, and T. Ostapchuk, Ferroelectric 288, 169 (2003).

17. P. Mounaix, M. Tondusson, L. Sarger, D. Michau, V. Reymond, and M. Maglione, Jpn. J. Appl. Phys., Part 1 44, 5058 (2005).

18. T. Ostapchuk, J. Petzelt, J. Hlinka, V. Bovtun, P. Kuzel1, I. Ponomareva, S. Lisenkov, L. Bellaiche, A. Tkach, and P. Vilarinho, J. Phys. Condens. Matter 21, 474215 (2009). 